\title{
COVID-19: Recent Trends in the World and Precautionary Measures
}

\author{
Hina Afzal Sajid ${ }^{1,2}$, Ahmad Ali ${ }^{3, *}$, Aqsa Afzal ${ }^{4}$ \\ ${ }^{1}$ Department of Education, Government of Punjab, Pakistan \\ ${ }^{2}$ Center of Excellence in Molecular Biology, University of Punjab, Lahore, Pakistan \\ ${ }^{3}$ Department of Medicine, Cholistan University of Veterinary and Animal Sciences, Bahawalpur, Pakistan \\ ${ }^{4}$ FMH College of Medicine and Dentistry, Lahore, Pakistan
}

Email address:

hinaafzal_17@yahoo.com (H. A. Sajid),ahmadali@cuvas.edu.pk(A. Ali),aqsaafzal044@gmail.com (A. Afzal)

${ }^{*}$ Corresponding author

\section{To cite this article:}

Hina Afzal Sajid, Ahmad Ali, Aqsa Afzal. COVID-19: Recent Trends in the World and Precautionary Measures. American Journal of Life Sciences. Vol. 8, No. 3, 2020, pp. 41-44. doi: 10.11648/j.ajls.20200803.12

Received: July 22, 2020; Accepted: August 5, 2020; Published: August 13, 2020

\begin{abstract}
A novel coronavirus has become a major health issue worldwide, initially founded in Wuhan, province of china, in the end of December 2019 and infected people of most countries globally. In February 2020, World Health Organization (WHO) termed it as COVID-19. The pandemic encompasses a variety of symptoms such as severe pneumonia along with respiratory disorder, multi-organ failure and septic shock, on the other side; it can be asymptomatic as well. The chain of infection involves six step procedures to transmit the virus into an individual. Recklessly, FDA has not approved any medication yet for this infection. People with flimsy immune system and suffering from any illness are more susceptible to infection. At present, to minimize the risk of cases only the preventive measures are being implemented. Social distancing is highly advised, mainly in vicinities having communal transmission. Quarantine is also considered one of the ancient and eventual tools of controlling the outbreaks that are communicable. Use of face masks as well as personal and environmental hygiene is very important to evade the risk of this virus. World Health Organization played an active role by implementing quite a lot of standards actions to avoid the spread of COVID-19 pandemic. These comprised various type of lockdown (full/smart), quarantine, travel limitations, shutting of educational institutes and certain sorts of workstations. With the help of greater testing ability, severer quarantine rules and identifying more infectious people in the town, risk of secondary cases can be minimized. Scientists from all over the World are determined and making efforts by their hard work to develop vaccine for this incurable disease. So, it's time to greatly appreciate and cherish the Medical and Para-medical staff for their dedication and their heroic commitment to responsibility in the difficult duration of this outbreak.
\end{abstract}

Keywords: COVID-19, Quarantine, WHO, Pandemic

\section{Introduction}

A novel coronavirus, at present designated as SARS-CoV2 was recognized as major root of an occurrence for precarious respiratory infection in Wuhan, province of China by the end of 2019.[1] In Later on, it was designated as COVID-19 by the World Health Organization (WHO) in February 2020, which named after its occurrence in 2019. The clinical demonstration of 2019-nCoV ailment encompasses a variety of symptoms such as severe pneumonia along with respiratory disorder, multi-organ failure and septic shock, which causes the consequences of death on the other side; it can be asymptomatic as well [2]. In end of Jan 2020, the COVID-19 outbreak was declared as an emergency concern for public health by WHO internationally, and then in March 2020, it was illustrated as a pandemic with the aim of highlighting the significance of the circumstances to impulse entire world to take necessary action for the detection of infection by preventing its spread [3]. 


\section{Epidemiology}

The World Health Organization (WHO) was informed about the no. of cases of pneumonia collected from Wuhan, city of China in the last month of 2019. Afterward, On 12 January, 2020 , the announcement was made about the identification of the coronavirus in samples collected from the reported cases. The initial genetic analysis of virus revealed the reason of this outbreak. Globally, as of 3:36pm CEST, 3 August 2020, there have been 17,918,582 confirmed cases of COVID-19, including 686,703 deaths, reported to WHO [4].

Table 1. *Trend of COVID-19 towards different countries.

\begin{tabular}{|c|c|c|c|c|}
\hline Country & Date of first case Reported $\mathrm{mm} / \mathrm{dd} / \mathrm{yyyy}$ & Confirmed Cases & Deaths & Trends \\
\hline Brazil & $2 / 26 / 2020$ & $2,394,513$ & 86,449 & $\mathrm{Up}$ \\
\hline USA & $1 / 22 / 2020$ & $4,178,021$ & 146,460 & Up \\
\hline India & $1 / 30 / 2020$ & $1,385,635$ & 32,060 & Up \\
\hline Mexico & $2 / 28 / 2020$ & 385,036 & 42,645 & $\mathrm{Up}$ \\
\hline Chile & $3 / 3 / 2020$ & 343,592 & 9,020 & Down \\
\hline Columbia & $3 / 6 / 2020$ & 240,795 & 8,269 & Up \\
\hline Iran & $2 / 19 / 2020$ & 288,839 & 15,484 & Up \\
\hline Peru & $3 / 6 / 2020$ & 375,961 & 17,843 & Up \\
\hline Russia & $1 / 31 / 2020$ & 805,332 & 13,172 & Down \\
\hline South Africa & $3 / 5 / 2020$ & 434,200 & 6,655 & Up \\
\hline Kyrgyzstan & $3 / 18 / 2020$ & 32,124 & 1,249 & Up \\
\hline Iraq & $2 / 24 / 2020$ & 107,573 & 4,284 & Up \\
\hline Indonesia & $3 / 2 / 2020$ & 97,286 & 4,714 & Up \\
\hline United Kingdom & $1 / 31 / 2020$ & 300,270 & 45,823 & Down \\
\hline Egypt & $2 / 14 / 2020$ & 91,583 & 4,558 & Down \\
\hline Bolivia & $3 / 11 / 2020$ & 68,281 & 2,535 & Up \\
\hline Pakistan & $2 / 25 / 2020$ & 273,113 & 5,822 & Down \\
\hline Saudi Arabia & $3 / 2 / 2020$ & 264,973 & 2,703 & Down \\
\hline Bangladesh & $3 / 8 / 2020$ & 221,178 & 2,874 & Down \\
\hline
\end{tabular}

*Data from JHONS HOPKINS University \& Medicine Website last updated 7/27/2020. New cases confirmed each day (5-day-average) [5].

\section{Chain of Infection}

The sequence of infection mentions the route that viruses use to go into an individual and to transmit from one individual to another. There are six steps in the chain of infection and we know that transmission will only take place if all six elements in the chain are present. In order for an infection or disease to happen, six elements must be in place. This process is known as the chain of infection. Infectious agent is categorized as first element of the chain which can cause a disease. It could be a virus, bacteria, or fungi. The second element is the reservoir, somewhere the infectious agent subsists. It can be an abiotic place such as water or soil, or it can be a human or an animal. Then we have a port of exit, which is the way the agent leaves the body. This can happen through the mouth, if a person coughs or sneezes, through a cut, if a person is bleeding, during diaper changes or toileting. The following component is the method of transmission, which describes how the infectious agent is transmitted after one person to another. It can be in form of droplets, by airborne transmission or through primary and secondary contact. The fifth constituent in the chain of infection is the port of entry, or the room where the infective agent enters another person's body. This is similar to the port of exit; it can be a mouth, nose, eyes, an open cut etc. Finally, we have a susceptible host - it's a baby, an elderly person or someone with a weakened immune system. There is a terrible need to break one of the links in the infection chain to prevent the extent of disease.

\section{Transmission}

COVID-19 is transmitted through close contacts, over respiratory droplets and air born. But respiratory droplets and close contact are the main reasons of its transmission [6]. Results of Droplet infection show the presence of virus in the water particles (typically $5-10 \mu \mathrm{m}$ in diameter) that were transmitted. People not maintaining the distances more than 1 meter were found infected through air droplets directly. Besides, there are also many indirect sources of droplet contamination that has been documented [7].

\section{Clinical Symptoms}

The clinical demonstration of COVID-19 ailment encompasses a variety of symptoms such as severe pneumonia along with respiratory disorder, multi-organ failure and septic shock, which causes the consequences of death, on the other side; it can be asymptomatic as well. However, other clinical manifestation which are perceived are coughing, fatigue, fever, sore throat, headache, diarrhea, pressure and pain on chest, has been observed in different cases [8].

\section{Risk Groups}

According to one survey the people with age more than 65 years are at high risk to COVID-19 as compare to age group 45 to 64 years, 18 to 44 years and less than 18 years of age 
respectively. Males are at high risk to COVID-19 as compare to females [9]. In addition, people with the fragile immunity are more susceptible to COVID-19 [10].

\section{Prevention and Control}

Recklessly, FDA has not approved any medication yet for this infection, gone through effective study to demonstrate the effect of the virus on this worldwide pandemic through their controlled studies. Although there are therapies for disorders and advances are being made day by day to improve this area. Along with health, politics, economics and social order are the resilient and the most effective armament that society has contrary to this affecting virus to prevent the spread [11]. Presently, to minimize the risk of cases only the preventive measures are being implemented. Primary screening, identification, separation, and treatment are essential to avoid further spread. Preventive approaches are focused on patient's isolation to control the infection carefully, together with applicable trials to be adopted throughout the analysis to maintain the facility of clinical care to the diseased patient [12].

\subsection{Social Distancing}

Social distancing is highly advised, mainly in vicinities having communal transmission. Numerous Countries around the globe have installed seclusion and are practicing social/physical distancing as measures to avert the further extent of the virus.

\subsection{Quarantine}

Quarantine is considered one of the ancient and eventual tools of controlling the outbreaks that are communicable.

\subsection{Increasing Testing Capacity}

By increasing this capacity, it becomes easier to pinpoint the cases, isolate them, and trace all those individuals who have been in communication to void the spread of pandemic throughout the society. For this purpose, it is utmost priority to increase research laboratory' test capability so that novel testing strategies can be developed. Unlike techniques such as rapid-testing kits, serologic procedures and self-collected sample tests are being used in all over the world to recognize the cases in order to assist the quarantine rules.

\subsection{Personal and Environmental Hygiene}

Personal and environmental hygiene is very important to avoid this virus. It includes washing hand properly and frequently, use of WHO recommended sanitizers and disinfectants [13].

\subsection{Personal Protective Equipment}

To decrease the risk of COVID-19 transmission from possibly the infected people as well as from asymptomatic people, use of face masks is highly recommended [14]. The practice of using face masks is serving as means of source control in the public community. This practice is particularly useful in the pandemic situations where the ratio of asymptomatic but contagious individuals in the communal society can be supposed to be high. This practice of wearing face masks is highly considered for people obviously when visiting eventful, closed spaces, such as shopping centers, grocery stores, religious places; when travelling via public transportation; and for certain professions and workplaces where people are in physical proximity to quite a lot of other persons (for instance fellows of cashiers and the police force, - if there is not a glass screen between them etc.) and when telecommuting is impossible.

Table 2. Key Preventive Measures to control the COVID-19.

\begin{tabular}{l} 
Quarantine Measures \\
\hline Voluntary/Self Quarantine \\
Mandatory Quarantine \\
1) At Homes \\
2) At hotels \\
3) At hospitals \\
4) At quarantine centers \\
5) Others that are made by governments \\
\hline
\end{tabular}

\section{Other Measures}

Isolation

Personal Hygiene

Hand Washing

Avoid gathering

Personal Protective Equipment

Educational Institutes measures/closure

Offices measures/closure

\section{WHO and COVID-19}

WHO played an active role by implementing quite a lot of standards actions to avoid the risk of COVID-19 pandemic. These comprised various type of lockdown (full/smart), quarantine, travel limitations on people coming from abroad where the risk of disease is high, social distancing, for natives returning from localities of high risk, shutting of educational institutes and certain sorts of workstations. WHO advised all the countries to make an announcement that all the educational institutes from basic to higher level remain closed. Government of every country made a lot of effort to control the movement of publics. The restrictions were made for the citizens older than 50 years, individuals with flimsy immune system and for those who are suffering from any illness, from exit their home places and consuming public conveyance [15].

\section{Conclusion}

In this pandemic scenario, it can be concluded that people must follow the precautionary measures to avoid the spread of this infectious disease because it has not any approved medication or treatment yet. Scientists from all over the World are determined and making efforts by their hard work to develop vaccine for this incurable disease. Some basic 
points such as hand hygiene, self- isolation and communal distancing must be implemented by every citizen to play their part in avoiding the spreading of virus in society. With the help of greater testing ability, severer quarantine rules and identifying more infectious people in the town, risk of secondary cases can be minimized.

\section{Acknowledgements}

We greatly appreciate and cherish the Medical and Paramedical staff for their dedication and their heroic commitment to responsibility in the difficult duration of this outbreak.

\section{References}

[1] Wu Z, McGoogan JM. Characteristics of and Important Lessons from the Coronavirus Disease 2019 (COVID-19) Outbreak in China: Summary of a Report of 72314 Cases from the Chinese Center for Disease Control and Prevention. JAMA 2020; 323 (13): 1239-1242.

[2] Guan W, Ni Z, Hu Y, Liang W, Ou C, He J, et al. Clinical characteristics of coronavirus disease 2019 in China. N Engl J Med. 2020; 382 (18): 1708-20.

[3] Kumar, Dharmendra, Rishabha Malviya, and Pramod Kumar Sharma. "Corona virus: a review of COVID-19." Eurasian Journal of Medicine and Oncology 4 (2020): 8-25.

[4] Organiztion WH. WHO Corona Virus Disease (COVID-19) Dashboard. 2020. Available from: https://covid19.who.int/

[5] HOPKINS J. New cases of COVID-19 in World countries. 2020. Available from: https://coronavirus.jhu.edu/data/newcases.

[6] Liu J, Liao X, Qian S, Yuan J, Wang F, Liu Y, et al. Community transmission of severe acute respiratory syndrome coronavirus 2, Shenzhen, China, 2020.
[7] Ong SWX, Tan YK, Chia PY, Lee TH, Ng OT, Wong MSY, et al. Air, surface environmental, and personal protective equipment contamination by severe acute respiratory syndrome coronavirus 2 (SARS-CoV-2) from a symptomatic patient. Jama. 2020; 323 (16): 1610-2.

[8] Munster VJ, Koopmans M, van Doremalen N, van Riel D, de Wit E. A novel coronavirus emerging in China-key questions for impact assessment. N Engl J Med. 2020; 382 (8): 692-4.

[9] Surveillances V. The epidemiological characteristics of an outbreak of 2019 novel coronavirus diseases (COVID-19) China, 2020. China CDC Wkly. 2020; 2 (8): 113-22.

[10] Adhikari SP, Meng S, Wu Y-J, Mao Y-P, Ye R-X, Wang Q-Z, et al. Epidemiology, causes, clinical manifestation and diagnosis, prevention and control of coronavirus disease (COVID-19) during the early outbreak period: a scoping review. Infect Dis poverty. 2020; 9 (1): 1-12.

[11] Organiztion WH. Coronavirus disease (COVID-19) advice for the Public: When and how to use mask. 2020. Available from: https://covid19.who.int/

[12] Khan, Tarek Mahbub. "Preventive and Control Measures of COVID-19 Patients: A Review." Bangladesh Journal of Infectious Diseases (2020): S41-S44.

[13] Ferreira-Júnior, João B., Eduardo DS Freitas, and Suene FN Chaves. "Exercise: A Protective Measure or an "Open Window" for COVID-19? A Mini Review." Frontiers in Sports and Active Living 2 (2020): 61.

[14] Sajed, Ahmad Naeem, and Kapil Amgain. "Corona Virus Disease (COVID-19) Outbreak and the Strategy for Prevention." Europasian Journal of Medical Sciences 2.1 (2020): 1-3.

[15] Aggarwal, Vandana. "Effective ways to make corona virus lockdown: Productive and positive." Purakala with ISSN 0971-2143 is an UGC CARE Journal 31. 4 (2020): 17981807. 